\title{
Estimating the incidence of hip fractures in East Germany from hospital discharge statistics
}

\author{
Manfred Wildner, Waldtraut Casper, Karl E Bergmann
}

Hip fracture (proximal femoral fracture) is the most serious subtype of osteoporotic fractures. Its exponentially rising incidence with age is causing concern in countries with ageing populations. ${ }^{2}$ Although direct hospital costs for Germany have been estimated to be as high as 2 billion DM (1.2 billion US\$) per year, epidemiological data for this "silent epidemic" are difficult to acquire. ${ }^{3-5}$ The typical health related and social sequelae of proximal femoral fracture are hospital admission for surgical treatment, subsequent transfer to a rehabilitation hospital, considerable morbidity and mortality, and, often, the subsequent loss of independence in daily life.

This study aimed to estimate population based age specific and sex specific incidence figures for hip fractures in East Germany (16.5 million inhabitants) using national hospital discharge data for 1989, the last year of the German Democratic Republic (GDR), available at the Robert Koch-Institut, Berlin.

\section{Methods}

With few exceptions, patients with hip fractures are admitted to hospital. Hospital discharge statistics for closed femoral fractures (ICD-9 diagnostic codes 820.0, 820.2, and 820.8 ) can therefore be used to estimate age specific and sex specific incidence rates. These estimates require adjustment for unwanted registrations due to misclassification, erroneous double registrations, and second registrations after hospital transfer or readmission.

Misclassification in this context stands for information bias following the attribution of an erroneous ICD-9 code to a closed transcervical or trochanteric fracture of the proximal femur (false negative classifications) or the erroneous coding of an open fracture of this anatomic region or of a fracture outside this region (false positive classifications) as codes $820.0,820.2$, or 820.8

With regard to hospital transfers, information included in the discharge statistics of the GDR on whether a patient left the hospital, was transferred, or died could be used to correct the total number of hospital cases for transfers. Erroneous double registrations can be identified by a data processing step and are of minor importance $(0.2 \%)$. Hospital readmissions are, in principal, identifiable if subsequent annual data sets are combined by a unique, pseudonymised personal identification number (PIN) which was in use in the GDR. Only two thirds of patients have this PIN in the data, however, as it was recorded in the personal ID card which was often exchanged for a travel passport without a PIN by the elderly population.

Precise adjustment for readmissions and misclassifications would have required a validation study. An estimate of the magnitude of the effect of these two sources of information bias is given, however, in the discussion section.

\section{Results}

The total numbers of hospital discharges in 1989 for closed femoral fractures were 3015 for men and 10676 for women. Adjusting these figures for transfers between hospitals and departments $(23.7 \%)$ allows us to estimate incident cases-ie 2388 for men and 8028 for women. There were 2106 deaths in hospital in patients with closed femoral fractures, giving a hospital case fatality rate of about $20 \%$. Analysis of the hospital case fatality rate will be reported separately. Estimates of age specific and sex specific rates from these data are presented in table 1 .

\section{Discussion and conclusion:}

Estimates of incidence rates from utilisation data can only be approximate. An advantage of the secondary analysis of the GDR's national hospital discharge statistics is the efficient use of population based, easily accessible, and individualised data for estimating incidence rates. A disadvantage is its primary design as a hospital utilisation statistic without much medical information. The study design is limited to a historical-retrospective approach. Still, this design can provide, in suitable situations, an efficient way of obtaining much needed information that otherwise is hard to come by, and in the case of East Germany may be limited to a historical perspective.

Information bias due to misclassification is of concern in the use of routinely collected data. This source of error is limited for hip fractures as the hospital diagnosis of a proximal femoral fracture is straightforward from plain radiographs. Classification difficulties may arise in differentiating between transcervical (ICD-9 code 820.0) and pertrochanteric fractures (820.2), which are classified in this instance as hip fracture of unspecified location $(820.8)$. As this code is included in our analysis, it does not alter the study results. The proportion of $5.6 \%$ fractures classified as code 820.8 on discharge compares favourably with the figure of $16 \%$ reported by Karagas et al ${ }^{6}$ for the hospital claims of a $5 \%$ Medicare sample in the USA, and supports indirectly the validity of the GDR hospital discharge codes. It 
Table 1 Estimated age specific and sex specific incidence rates for hip fractures (ICD-9 820.0, 820.2, 820.8) for the German Democratic Republic, 1989

\begin{tabular}{|c|c|c|c|c|c|c|}
\hline \multirow[b]{2}{*}{ Age (y) } & \multicolumn{2}{|l|}{ Cases } & \multicolumn{2}{|l|}{ Population } & \multicolumn{2}{|c|}{ Cases / 100000 population * } \\
\hline & Male & Female & Male & Female & Male & Female \\
\hline $0-54$ & 705 & 385 & 6370300 & 6117100 & $11.1(10.3)$ & $6.3(5.6)$ \\
\hline $55-59$ & 187 & 261 & 456600 & 482100 & $41.0(38.1)$ & $54.1(50.3)$ \\
\hline $60-64$ & 171 & 430 & 353300 & 474400 & $48.4(45.0)$ & $90.6(84.3)$ \\
\hline $65-69$ & 237 & 712 & 250500 & 468500 & $94.6(88.0)$ & $152.0(141.4)$ \\
\hline $70-74$ & 141 & 701 & 126800 & 261000 & $111.2(103.4)$ & $268.6(249.8)$ \\
\hline $75-79$ & 314 & 1672 & 163000 & 369100 & $192.6(179.1)$ & $453.0(421.3)$ \\
\hline $80-84$ & 330 & 2015 & 103800 & 250100 & $317.9(295.6)$ & $805.7(749.3)$ \\
\hline $85+$ & 303 & 1852 & 49200 & 138100 & $615.9(572.8)$ & $1341.1(1247.2)$ \\
\hline Total & 2388 & 8028 & 7873500 & 8560400 & $30.3(28.2)$ & $93.8(87.2)$ \\
\hline
\end{tabular}

^ Estimate in brackets adjusted for an assumed overestimate of $7 \%$.

was pointed out recently that $80-90 \%$ of unspecified hip fractures are actually cervical fractures. ${ }^{78}$ ICD-9 code 821 encompasses fractures of other parts of the femur, and may include ill-specified proximal femoral fractures. Published age specific and sex specific incidence rates for the $\mathrm{GDR}^{9}$ are similar to rates published for the USA ${ }^{10}$ and do not seem to be inflated by unclassified hip fractures. Closed fractures belonging to code 821 may have been misclassified under $820.0,820.2$, or 820.8 . As the diagnosis of proximal femoral fractures is generally straightforward, we regard this source of error as negligible. Only $3 \%$ of all hospital discharges for fractures of the proximal femur were for open fractures. A distinction between open and closed fractures can be made clinically or intraoperatively, and any misclassification should have, at most, only a small effect on the estimated incidence rates of closed fractures of the proximal femur.

To estimate the effect of repeat admissions under the same diagnostic code, eg for reoperations, 7073 approximated incident cases $(67.9 \%$ of all cases) with a unique personal identification number were studied. Of these, $6.8 \%$ were repeat admissions within the year 1989 under the diagnostic codes included in our study, suggesting an overestimation of true incident cases of this magnitude. Table 1 also provides figures which are adjusted accordingly (repeated admissions and double registrations).

Incidence rates derived from hospital registry data have been reported for other countries. ${ }^{111}$ From comparison of these it appears that hip fracture rates in the GDR in 1989 increased slightly compared with GDR figures from 1983. They are similar to figures reported to the MEDOS study group from the UK and the Netherlands, but lower than Scandinavian rates. ${ }^{11}$ The proportion of men among hospital discharges $(28 \%)$ is similar to that in most European countries. The median duration of hospital admission per discharge of 26 days increases to about 34 days after adjustments for transfers. Our total adjustment of $30.7 \%$ for transfers, readmissions, and double registrations for an estimate of new cases from discharge statistics is almost identical to the Swedish figure of $32 \%^{11}$-a substantial source of bias if apparent hip fractures rates are the basis for comparisons.

The year 1989 was the last year for which complete hospital discharge statistics were compiled in the GDR under East German law. The German unification in autumn 1990 was followed by considerable changes in both the social security system, the health care system, and the legislation. Although hospital discharge statistics continue to be compiled for the Federal Republic of Germany, changes in the reporting system mean that only aggregate information, and no longer individual data, are available for analysis. The availability of individual, pseudonymised data for the fairly homogenous and geographically confined GDR population is therefore restricted to the years before 1989. This example of closed hip fractures may serve as a model approach for other diseases.

Hospital discharge statistics allow an estimate of true incidence figures for any disease or problem identifiable reliably by ICD coding that has a high probability of hospital admission, has only minor pre-hospital recovery or mortality, and has typically either functional recovery or death as an outcome. Examples are childbirth and related complications, severe infectious diseases, and surgical conditions like appendicitis. Incidence estimations for chronic conditions pose a problem as they may lead to repeated hospital admissions over longer periods of time. Health services research by analysis of hospital utilisation may be of interest for those conditions. Information on the location of the reporting hospital and on the home area of the patient is provided in the GDR data, possible further applications are the analysis of small area variations and time trends.

Funding: this work was funded in part by the Dr Liesel Keinath Foundation, administered by the Stifterverband der Deutschen Wissenschaft.

Conflicts of interest: none.

1 WHO Study Group. Assessment of fracture risk and its application to screening for postmenopausal osteoporosis. Technical Report Series 843. Geneva: WHO, 1994.

2 Bergmann KE, Wildner M, Casper W. Epidemiologie der Osteoporose. In: Großklaus R, Stück B, Somogyi A, von Stackelberg B, eds. Osteoporose - Prävention in Gegenwart und Zukunft. München: MMV Medizin Verlag (BgaSchriften 94/2), 1994.

3 Kunczik T, Ringe JD. Osteoporose: eine Herausforderung für die Zukunft. Dt Ärzteblatt 1994;91(16):854.

4 Wildner M, Casper W, Bergmann K.E. The future costs of hip fractures in Germany. World Health Forum 1995;16: 400-1.

5 Coster A, Haberkamp M, Allolio B. Inzidenz von Schenkelhalsfrakturen in der Bundesrepublik Deutschland im internationalen Vergleich. Soz Präventiv 1994;39(5):287-92.

6 Karagas MR, Lu-Yao GL, Barrett JA, Beach ML, Baron JA. Heterogeneity of hip fracture: age, race, sex, and geographic patterns of femoral neck and trochanteric fractures among the US elderly. Am $\mathcal{F}$ Epidemiology 1996;143:67782.

7 Karagas MR, Baron JA, Barrett JA. Authors' reply to letter. Heterogeneity of hip fracture: age, race, sex, and geographic patterns of femoral neck and trochanteric fractures among the US elderly. Am f Epidemiology 1996;144:803.

8 Levy AR, Mayo NE, Grimard G. Letter. Heterogeneity of hip fracture: age, race, sex, and geographic patterns of femoral neck and trochanteric fractures among the US elderly. Am $\mathcal{J}$ Epidemiology 1996;144:801-3.

9 Bergmann E, Menzel R. Krankenhausbehandlung nach Bergmann E, Menzel R. Krankenhausbehandlung nach
Krankheitsarten in der DDR 1989 Teil II. Berlin: RKI-Heft
5/1995:541.

10 Baron JA, Karagas M, Barrett J, Kniffin W, Malenka D, Mayor M, Keller RB. Basic Epidemiology of fractures of the upper and lower limb among Americans over 65 years of age. Epidemiology 1996;7:612-8.

11 Johnell O, Gullberg B, Allander E, Kanis JA and the MEDOS Study Group. The apparent incidence of hip fractures in Europe: a study of national register sources. Osteoporosis International 1992;2:298-302. 